\title{
TRTакаремі
}

ISSN 2149-9446 | Cilt 07 | Sayı 14 | Ocak 2022 | Sosyal Medya

\section{Sosyal Medya Platformları ve Televizyon Yayıncılığı: TRT'nin Dijital Pratikleri ${ }^{1}$}

\section{Ergin Şafak DikMEN*}

\begin{abstract}
Öz
Web 2.0 döneminin ikinci yarısından itibaren sosyal medya kullanıcı sayısının giderek artması, medya kuruluşlarını harekete geçirmiş ve televizyon kanallarının kurumsal sosyal medya hesapları birbiri ardına açılmaya başlamıştır. Illk başta televizyon yayıncılığı, yayınlanacak içeriklerin bu "yeni" ortamda duyurulmasıyla yetinmiştir. Ancak kısa zaman içerisinde sosyal medya platformları, video paylaşım platformları ve web siteleri üzerinden içeriklerin paylaşıldığı, platformlar arasında içerik akışlarının oluşturulduğu bir sosyal TV yayıncılığına geçilmiştir. Televizyon yayıncılı̆̆ ile sosyal medya arasındaki bu çok yönlü etkileşim, karmaşık bir televizyon yayıncılığına zemin oluşturmaktadır. Bu gelişmeler doğrultusunda bu araştırma, "Televizyon yayıncılığının kurumsal sosyal medya pratikleri nelerdir?" sorusuna yanıt aramaktadır. Bu kapsamda TRT çatısı altında yayın yapan 12 televizyon kanalının kurumsal sosyal medya hesapları 01.09.2021- 30.09.2021 tarihleri arasındaki nicel araştırma yöntemi ve basit rastlantısal örneklem tekniği kullanılarak incelenmiştir. Elde edilen sonuçlar doğrultusunda TRT çatısı altında yayın yapan her bir televizyon kanalının ayrı bir sosyal medya hesabının olduğu oldukça girift bir yapılanmanın bulunduğu, hesaplar arasında içeriklerin yeniden dolayımlandığı ve içerik yönetim pratiklerinde farklılıklar oluştuğu ortaya çıkmıştır. Diğer yandan sosyal TV yapılanmasına bakıldığında televizyon yayıncılığı ve sosyal medya platformları arasında çok yönlü bir çapraz medya içerik dolaşımı oluşturulsa da transmedya tabanlı dijital anlatımların ve etkileşimli TV programların bulunmadığı belirlenmiştir. TRT Arşiv sitesi üzerinden, TRT'de yayımlanmış tarihi değere sahip içeriklerin internet üzerinden açık erişime açılması ise televizyon yayıncılığı için önemli bir adım oluşturmuştur.
\end{abstract}

Anahtar Kelimeler: Televizyon, Sosyal Medya, TRT, Sosyal TV, Yayıncılık

*Dr. Öğr. Üyesi, Ankara Üniversitesi Illetişim Fakültesi Radyo, Televizyon ve Sinema Bölümü, safakdikmen@gmail.com

Dikmen, E. Ş. (2022). Sosyal Medya Platformları ve Televizyon Yayıncılı̆ı: TRT’nin Dijital Pratikleri1. TRT Akademi, 7 (14), 134-153. DOI: $10.37679 /$ trta.1010512

\footnotetext{
${ }^{1}$ Bu çalışma Ankara Üniversitesi Iletişim Fakültesi, NETlab - Yeni Medya Araştırmaları Laboratuvarında gerçekleştirilmiştir http://netlab.media.
}

\section{Araştırma Makalesi}

Geliş Tarihi: 15.10 .2021

Revizyon Tarihi: 13.12.2021

Kabul Tarihi: 14.01.2022 


\title{
TRTakadeмi
}

\section{Social Media Platforms and Television Broadcasting: Digital Practices of Turkish Radio and Television Corporation ${ }^{2}$}

\author{
Ergin Şafak DikMEN
}

\begin{abstract}
The growing number of social media users has driven media companies and television channels to launch corporate social media accounts one after another during the second part of the Web 2.0 era. At first, only the content to be broadcast was announced on these platforms. However, within a short period of time, a social TV broadcasting model emerged, in which content is shared across social media platforms, video sharing platforms, and websites, as well as a new content streaming model. This interaction between television and social media, sets the framework for a more complex television broadcasting. In light of these developments, this study tries to address the question, "What are the corporate social media practices of television broadcasting?". In this context, the corporate social media accounts of 12 television channels broadcasting under the umbrella of Turkish Radio and Television Corporation (TRT) were examined using the quantitative research method and simple random sampling technique between 01.09.2021 and 30.09.2021. According to the findings, each television channel transmitting under the TRT umbrella has its own social media account, there is a complex structure, contents are re-mediated across the accounts, and there are differences in content management practices. However, when we examined the social TV structure, we discovered that, while there is a diverse cross-media content circulation between television broadcasting and social media platforms, there are no transmedia-based digital narratives or interactive TV programs.
\end{abstract}

Keywords: Television, Social Media, TRT, Social TV, Broadcasting

\footnotetext{
${ }^{2}$ This research was performed in Ankara University Faculty of Communication NETlab - New Media Research Lab. http:// en.netlab.media
}

\section{Research Paper}

Recieved: 15.10.2021

Revised: 13.12.2021

Accepted: 14.01.2022 


\section{Giriş}

İnternet teknolojisiyle birlikte televizyon yayıncılı̆̆ı köklü bir değişime uğramıştır. Bu değişim özellikle sosyal medya platformlarının gelişmesi ve küresel ölçekte yaygınlaşmasıyla hız kazanmıştır. WEB 2.0 (2000-2010) döneminin ortasından itibaren Facebook (2004) ve Twitter (2006) gibi sosyal medya platformlarında giderek daha fazla izleyicinin hesap açması televizyon yayıncılığını da harekete geçirmiştir. Bu platformlar ilk başta kullanıııların sayısal ortamda birbiriyle etkileşime geçmesi amacıyla kurulmuştur ancak medya kuruluşlarının da kurumsal sosyal medya hesapları açmasıyla birlikte internet tabanlı sosyal bir ekosistem oluşmuştur. Bunun sonucunda internet ve televizyon arasındaki keskin ayrım ortadan kalkmış, televizyon yayıncılığı biçim değiştirerek televizyon 4.0 olarak tanımlanan yeni bir yayıncılık dönemine geçmiştir (Gezgin, 2018, s. 584). Artık televizyon yayıncılığı sosyal medya platformlarını etkin biçimde kullanmakta ve izleyicilere pek çok farkıı içerik sunmaktadır. Türkiye'de televizyon kanalları özellikle Facebook, Instagram, Twitter ve YouTube'u kullanmakta, bununla birlikte yine bu platformlarda dizi oyuncularının, yapım şirketlerinin, habercilerin de yine bu sosyal medya platformlarında hesap açțkları ve paylaşımlarda bulundukları görülmektedir.

2010 yılından itibaren sosyal medya kullanıc sayısının giderek artması, medya kuruluşlarını harekete geçirmiş ve televizyon kanallarının kurumsal sosyal medya hesapları birbiri ardına açılmaya başlamıştı. IIlk başta televizyon yayıncılı̆̆ı, yayınlanacak içeriklerin bu "yeni" ortamda duyurulmasıyla yetinmiştir. Sonraki yıllarda ise içeriklerin çok sayıda farklı platform üzerinden paylaşıldığı, platformlar arası içerik akışlarının oluşturulduğu bir sosyal TV yayıncılığına geçilmiştir. Bu sürecin önemli bir aşaması ise televizyondan sosyal medyaya doğru tek yönlü bir içerik akışından, sosyal medya içeriklerinin de özellikle canlı yayınlanan programlarda yer aldığı, televizyonun ve sosyal medyanın etkileşim içinde olduğu bir yayıncılık modeline geçilmesidir. Sosyal medya ortamındaki kullanıcı sohbetlerine, televizyon yayıncılığı kendi iletileri ile katılmakta, hatta bunun da ötesine giderek izleyicilerin mesajları televizyon yayına dâhil edilerek sosyal medya içerikleri televizyon programlarının birer parçası hâline getirilmektedir (Harrington, Highfield, ve Bruns, 2013, s. 407-408). Televizyon yayıncılı̆ı ile sosyal medya arasındaki bu çok yönlü etkileşim, karmaşık bir televizyon yayıncılığına zemin oluşturmaktadır.

Bu gelişmeler doğrultusunda araştırmanın amacı, Türkiye'de kamusal yayıncılık yürüten Türkiye Radyo ve Televizyon Kurumu (TRT) bünyesindeki televizyon kanallarının sosyal medya platformlarını incelemek ve kurumun sosyal medya pratiklerini ortaya çıkarmaktır. Bu çerçevede araştırma, "Televizyon yayıncılığının kurumsal sosyal medya pratikleri nelerdir?” sorusuna yanıt aramaktadır. Araştırma 
kapsamında TRT çatısı altında yayın yapan 12 televizyon kanalının kurumsal sosyal medya hesapları 01.09. 2021-30.09.2021 tarihleri arasındaki nicel araştırma yöntemi ve basit rastlantısal örneklem tekniği kullanılarak incelenmiştir. Bu araştırma ile Türkiye'de kamu yayıncılığı yürüten televizyon kanallarının web ortamındaki pratikleri kapsamlı bir perspektiften ele alınmış ve alanyazındaki boşluğun giderilmesine katkı sağlanmıştır. Elde edilen sonuçlar doğrultusunda TRT çatısı altında yayın yapan her bir televizyon kanalının ayrı bir sosyal medya hesabının olduğu, oldukça girift bir yapılanmanın bulunduğu, hesaplar arasında içeriklerin yeniden dolayımlandığı ve içerik yönetim pratiklerinde farklılıklar oluştuğu ortaya çıkmıştır. Diğer yandan sosyal TV yapılanmasına bakıldığında televizyon yayıncılığı ve sosyal medya platformları arasında çok yönlü bir çapraz medya içerik dolaşımı oluşturulsa da transmedya tabanlı dijital anlatımların ve etkileşimli TV programların bulunmadığı belirlenmiştir. TRT Arşiv sitesi üzerinden, TRT'de yayımlanmış tarihi değere sahip içeriklerin internet üzerinden açık erişime açılması ise televizyon yayıncılığı için önemli bir adım oluşturmuştur.

\section{Literatür Taraması}

Medya platformlarının yakınsaması, bilgisayar tabanlı dijital teknolojilerin 1980'li yıllardan itibaren yayıncılık alanında kullanılmasıyla başlamıştır. 2000'li yıllarda başlayan WEB 2.0 dönemiyle birlikte, küresel ağ teknolojisi sosyal medya platformlarının gelişmesine ve tüm dünyada sosyal bir dijital ağın oluşmasına zemin hazırlamıştır. Televizyon yayıncılığının sosyal medya ile imtihanı yine aynı dönemde başlamış ve hâlen devam etmektedir. BBC'nin (2004) yayınladığı kamu değeri oluşturmak - BBC'yi dijital bir dünya için yenilemek başlıklı raporda, televizyon yayıncılığının içinde bulunduğu dijital dönüşüm sürecine dikkat çekilmiştir. Raporda özellikle izleyici katılımının BBC'nin yeni dijital yayıncılık stratejisi olduğu ve bu amaçla geliştirilen yeni platformlara vurgu yapılmıştır (BBC, 2004). Alanyazında izleyici katılımı ve izleyiciler arasındaki etkileşime odaklanan pek çok çalışma yürütülmüştür. Chorianopoulos ve Lekakos (2008) ilk başta etkileşimli televizyon terimi üzerinden tartışmalar yürütüldüğünü, zaman içerisinde bu terimin yerini "Sosyal TV" kavramının aldığına dikkat çekmektedir. Etkileşimli televizyonda; geleneksel televizyon yayıncılığındaki pasif izleyicinin yerini hem televizyon içerikleriyle hem de diğer izleyicilerle etkileşime geçebilen aktif bir izleyici almaktadır. Türkiye'de etkileşimli televizyon yayıncılığının ilk örnekleri arasında; 1993 yılında Kanal 6'da yayınlanan ve Tolga Gariboğlu'nun sunuculuğunu üstlendiği Hugo (1993) adlı televizyon programı örnek gösterilebilir. Danimarka merkezli ITE firması tarafindan geliştirilen bu sistemi; televizyon yayıncılığının dijital oyun ve telefonla birleştirerek izleyicinin aktif bir oyuncuya dönüştüğü etkileşimli 
televizyon sistemi olarak tanımlamak mümkündür. Bu sistemde, stüdyo dışından canlı yayına katılan izleyiciler, tuşlu sabit telefon kullanarak Hugo adlı karakteri yönlendirerek oyun içerisindeki belirli görevleri tamamlamaya çalışmakta, izleyiciler de bu oyun performansını canlı olarak televizyon ekranından izleyebilmektedir.

Diğer taraftan sosyal TV; izleyiciler arasında etkileşimi öne çıkaran daha geniş bir kavramdır. Televizyon yayını sırasında uzaktaki izleyicilerin birbirleriyle sesli ya da anlık yazılı mesajlarla iletişim kurmasını sağlayan; izleyicilerin arkadaşlarıyla birlikte televizyon izlediği hissini uyandıran görsel, işitsel bir sistem olarak tanımlamaktadır (Chorianopoulos ve Lekakos, 2008, s. 115). Sosyal TV'ye yönelik ilk çalışmalar, televizyon izlerken aynı anda izleyicilerin birbirleriyle yazılı mesajlaşmasını sağlayan etkileşimli televizyon sistemleri üzerine odaklanmıştır (O'Sullivan, 1995; Regan ve Todd, 2004). Sosyal TV'nin başlangıç şekli, akıllı televizyonlara yüklenen yazılımlar/uygulamalar aracılığıyla farklı işlevler gören bütünleşik bir akıllı televizyon sisteminin oluşturulmasını, bu sayede de izleyicilerin programları izlerken aynı zamanda birbirleriyle iletişim kurmasından ibarettir (Stollfuß, 2018, s. 39). Ancak günümüzde sosyal TV kavramı izleyicilerin günlük olarak kullandığı sosyal medya platformları ile televizyon yayıncılığının yöndeşmesi olarak algılanmaktadır. Sosyal TV 1.0 döneminde izleyicilerin bütünleşik bir televizyon sistemi üzerinden diğer izleyicilerle iletişim kurması hedeflenirken, sosyal TV 2.0 döneminde artık izleyici televizyon izlerken aynı zamanda cep telefonu ya da tablet bilgisayar gibi ikinci bir ekran kullanmaktadır. Bu sayede televizyon izleyicilerinin sadece birbiriyle iletişim kurmasının hedeflendiği dönemin ötesine geçilerek, izleyiciler yayın sırasında sosyal medya platformları üzerinden sohbet etmekte, fotoğraf ve/ veya video içerikleri üretmekte ve bunları etiketleyerek paylaşmaktadır (Stollfuß, 2018, s. 39-40). Schatz ve arkadaşları (2008) sosyal TV'nin geleceğine yönelik öngörülerinde televizyon ve sosyal medya arasındaki ilişkiye dikkat çekmiş, sosyal TV'nin televizyon sistemleri üzerinden yapay olarak izleyiciye sunulması yerine izleyicinin sıkça kullandığı platformlar ile uyumlu bir yayıncılık anlayışının oluşması gerektiğini savunmuştur. Bu anlamda ilk zamanlarda olduğu gibi akıllı televizyon sistemlerine yazılı iletişim özelliği kazandırmak yerine, günümüzde televizyon yayıncılığı izleyicilerin gündelik yaşamında kullandığı mikroblog (Twitter) sosyal ağ (Facebook) ya da fotoğraf-video paylaşım (Instagram) platformlarına entegre olmuştur (Stollfuß, 2018). Televizyon içerikleri ile kanalların sosyal medya platformları arasındaki ilişkiye bakıldığında; sosyal TV'nin geleneksel televizyon yayın akışıyla eşgüdüm içerisinde olduğu, kanalların kurumsal sosyal medyadaki içerik akışlarının geleneksel televizyon yayınıyla paralel olarak ilerlediği görülmektedir 
(Dikmen, 2017, s. 445).

Sosyal TV 1.0'dan sosyal TV 2.0'a geçiş aynı zamanda televizyon kuruluşları için de yeni bir dönemin başlangıcı olmuştur. Televizyon yayıncılığı sadece izleyicilerin birbiriyle iletişim kurmasını hedefleyen kapalı bir etkileşim sisteminden, izleyicilerin gün içerisinde sıkça ziyaret ettiği sosyal medya ortamına adım atmıştır. Bu anlamda söz konusu bu dijital ortamın kendi dinamiklerinin bulunması nedeniyle televizyon kuruluşlarının bu ortamda etkin olabilmesi için yeni pratikler geliştirmesi gerekmiştir. Kullanıcıların/izleyicilerin hem diğer kullanıcıları takip edip iletişime geçmesi hem de içerik üretip paylaşması, çok yönlü bir sosyal medya ekosistemi yaratmıştır. Televizyon kuruluşları için sosyal TV 2.0 döneminin en zorlu kısmı, yeni ve sosyal medya platformlarına özgü içerikler üretme zorunluğudur. Bu anlamda artık televizyon kuruluşları geleneksel televizyon yayınlarından türetilen içeriklerin sosyal medya platformları üzerinden paylaşılmasıyla sınırlı kalması mümkün değildir.

Çapraz medya içerikleri dijital yayıncılık ekosisteminin en önemli unsurlarından bir tanesidir. Artık içerikler sadece televizyon yayınlarıyla sınırlı kalmamakta aynı zamanda, WEB siteleri, mikro blog, video ve fotoğraf paylaşım platformları üzerinden de seyirciye ulaşmaktadır. Kültür endüstrisi, 1990'lı yıllardan itibaren farklı dijital öykü anlatımları geliştirerek bu içerikleri sinema, televizyon, WEB ve dijital oyun gibi pek çok farklı mecrada yayımlamaya başlamıştır. Transmedya içerikleri; farklı mecralar üzerinde yayımlanan ve her öykü parçasının ana öyküye katkı sağladığı, bu öykülerin birbirini bütünlediği ama aynı zamanda da birbirinden bağımsız olarak takip edilebildiği bir öykü anlatım biçimi olarak tanımlanmaktadır (Jenkins, 2006, s. 95-96). Nursel Bolat (2019, s. 528), çapraz medya ve transmedyanın birbirine oldukça yakın anlat yapıları olmasına karşın çapraz medya temelindeki bir anlatının ilerleyen aşamalarda transmedya anlatım biçimine dönüşebileceğine dikkat çekmektedir.

Transmedyanın daha yeni bir kavram olmasına karşın çoklu medya ortamlarında medyalar arası geçişlerin ve içerik köprülerinin uzun zamandır kullanıldığı görülmektedir (Bolat, 2019). Bu çerçevede Olcay Holat (2021, s. 519), içerikler arasında kurulan ağ yapısını şu şekilde tanımlamaktadır: "Farklı mecralarda yayılım gösteren içerikler, ana metne olan ilgiyi ve isteği arttırma amacı taşırken, dijital platform dizisine yönlendirmek için köprü görevi gören özelliklere sahiptir (...) tüm bu içerikler, kullanıcıların farklı gereksinimlerine ve duyusal isteklerine göre tasarlanmıştır." Buna göre farklı mecraların diğerlerinden ayrışan bir anlatım dili ile hikâyeye farklı düzeylerde katkı sunarak hikâyenin çok katmanlı yapısına katkıda bulunmaktadır (Holat, 2021). 
Diğer yandan Alper Yılmaz'ın (2020, s. 49-50) radyo ve medya yakınsamasını ele aldığı çalışmada; (1) geleneksel medyanın değişime uğramasıyla yeni medya platformlarının geleneksel medyanın işlevlerini yerine getirdiği, (2) geleneksel radyo yayınlarının eksiklerinin yeni medya platformlarının etkileşim ve görsel yapısı sayesinde giderildiği (3), son olarak da geleneksel ve yeni medyanın eş güdüm içerisinde hareket etmesiyle tek kapsamlı bir medya yapısı oluştuğu vurgulanmıştır.

Televizyon yayıncılığına geniş bir perspektiften bakıldığında internet ve geleneksel televizyon yayıncılığı hem ekonomik hem de sosyolojik açıdan bağlantılıdır, içeriğe farklı platformlar üzerinden erişilse de asıl önemli olan, iletilen mesaj ve alıcı üzerinde bıraktı̆̆ etkinin farklı değişkenler ile desteklenip desteklenmediği$\operatorname{dir}$ (Gezgin, 2018, s. 558). Türkiye'de televizyon yayıncılığı ve yeni medya ilişkisi üzerine yürütülen çalışmaların sayısı giderek artsa da kamu yayıncılığı yürüten televizyon kanallarının WEB ortamındaki pratikleri kapsamlı ve geniş bir perspektiften ele alınmamıştır. Yürütülen bu çalışma ile alanyazındaki bu boşluğun giderilmesine katkı sağlanmıştır. Bu çerçevede bir sonraki bölümde saha araştırmanın sınırları ve kullanılan araştırma yöntemi aktarılacak, ardından elde edilen bulgular ve ulaşılan sonuçlar ele alınacaktır.

\section{Metodoloji}

Bu araştırmanın amacı, Türkiye'de kamusal yayıncılık yürüten TRT bünyesindeki televizyon kanallarının sosyal medya platformlarını incelemek ve kurumun sosyal medya pratiklerini ortaya çıkarmaktır. Bu çerçevede TRT çatısı altında yayın yapan 12 televizyon kanalının kurumsal sosyal medya platformları, içerik paylaşım pratikleri ve takipçi verileri incelenerek kurumun çapraz medya içerik yönetim pratikleri ortaya çıkarılmaya çalışılmıştır.

Sosyal medya ortamındaki kullanıcı paylaşımları ve televizyon kuruluşlarının kurumsal hesaplarından paylaştı̆ı içerikler aynı siber ortamda harmanlanmaktadır. Dolayısıyla bu dijital sohbet ve ileti ortamında yayıncı ve izleyici aynı platformda bir araya gelmektedir. Bu çerçevede televizyon yayıncılığının sosyal medya ortamında izleyici ile kurduğu iletişimde çok yönlü ve karmaşık bir sosyal medya içerik üretim ve paylaşım zinciri bulunmaktadır. Bu kapsamda araştırma, "Televizyon yayıncılığının kurumsal sosyal medya pratikleri nelerdir?" sorusuna yanıt aramaktadır.

Çalışmanın araştırma evrenini TRT çatısı altında yayın yapan 12 kanala (TRT 1, TRT 2, TRT World, TRT Haber, TRT Spor, TRT Avaz, TRT Belgesel, TRT Müzik, TRT Arabi, TRT Türk, TRT Kurdî , TRT Çocuk) ait Twitter, Instagram, Facebook ve YouTube 
kanalı oluşturmaktadır. Bu araştırma evreni, nicel araştırma yöntemi ve basit rastlantısal örneklem tekniği kullanılarak incelenmiştir. Araştırmanın ilk aşamasında 01.09.2021- 30.09.2021 tarihleri arasında incelenen toplam 48 sosyal medya hesabının takipçi/abone, gönderi, takip edilen, YouTube video görüntüleme sayıları kayıt altına alınmıştır (Tablo 1). Buna ek olarak Twitter ve YouTube kanalarının açılış yılları araştırmaya dâhil edilmiştir. Instagram ve Facebook kanallarının açılış tarihleri platformların bu bilgiyi vermemesi nedeniyle araştırma evreninin dışında tutulmuştur. İkinci aşamada, en çok takipçi sayısına sahip Twitter ve Youtube hesapları basit rastlantısal örneklem kullanılarak incelenmiştir. Bu kapsamda içerik analizi yöntemiyle incelenen hesapların ekran kayıtları ilk önce numaralandırılmış, ardından random.org sayfasında oluşturulan rastlantısal sayılar listesine göre belirlenen içerikler incelenmiştir. Diğer taraftan TRT Avaz kanalı yukarıda sözü edilen sosyal medya hesaplarına ek olarak Pinterest, VK (https://vk.com/ trtavaz) ve OK (https://ok.ru/group/54387896484012) platformlarında da kurumsal hesaplara sahip olduğu, benzer bir şekilde TRT Spor kanalının da kurumsal TikTok hesabının olduğu belirlenmiş ancak söz konusu bu kurumsal hesaplar araştırma evreninin dışında tutulmuştur.

Tablo 1. İncelenen Sosyal Medya Hesaplarının İnternet Ortamındaki Erişim Adresleri

\begin{tabular}{|l|c|c|c|c|c|}
\hline $\begin{array}{c}\text { Televizyon } \\
\text { kanalı }\end{array}$ & $\begin{array}{c}\text { Kanal Web } \\
\text { Adresi }\end{array}$ & $\begin{array}{c}\text { Facebook } \\
\text { Erişim } \\
\text { Adresi }\end{array}$ & $\begin{array}{c}\text { Twitter } \\
\text { Erişim } \\
\text { Adresi }\end{array}$ & $\begin{array}{c}\text { YouTube } \\
\text { Erişim } \\
\text { Adresi }\end{array}$ & $\begin{array}{c}\text { Instagram } \\
\text { Erişim Adresi }\end{array}$ \\
\hline TRT 1 & $\begin{array}{c}\text { https://www. } \\
\text { trt1.com.tr/ }\end{array}$ & $\begin{array}{c}\text { https://www. } \\
\text { facebook. } \\
\text { com/TRT1 }\end{array}$ & $\begin{array}{c}\text { https:// } \\
\text { twitter.com/ } \\
\text { TRT1 }\end{array}$ & $\begin{array}{c}\text { https:// } \\
\text { www.you- } \\
\text { tube.com/ } \\
\text { trttv1 }\end{array}$ & $\begin{array}{c}\text { https://www. } \\
\text { instagram. } \\
\text { com/trt1 }\end{array}$ \\
\hline TRT 2 & $\begin{array}{c}\text { https://www. } \\
\text { trt2.com.tr/ }\end{array}$ & $\begin{array}{c}\text { https://www. } \\
\text { facebook. } \\
\text { com/trt2 }\end{array}$ & $\begin{array}{c}\text { https:// } \\
\text { twitter.com/ } \\
\text { trt2tv }\end{array}$ & $\begin{array}{c}\text { https:// } \\
\text { www.you- } \\
\text { tube.com/ } \\
\text { trt2 }\end{array}$ & $\begin{array}{c}\text { https://www. } \\
\text { instagram. } \\
\text { com/trt2/ }\end{array}$ \\
\hline TRT World & $\begin{array}{c}\text { https://www. } \\
\text { trtworld.com/ }\end{array}$ & $\begin{array}{c}\text { https://www. } \\
\text { facebook. } \\
\text { com/trtworld }\end{array}$ & $\begin{array}{c}\text { https:// } \\
\text { twitter.com/ } \\
\text { trtworld }\end{array}$ & $\begin{array}{c}\text { https:// } \\
\text { www.youtu- } \\
\text { be.com/c/ } \\
\text { trtworld }\end{array}$ & $\begin{array}{c}\text { https://www. } \\
\text { instagram. } \\
\text { com/trtwor- } \\
\text { Id/ }\end{array}$ \\
\hline TRT Haber & $\begin{array}{c}\text { https://www. } \\
\text { trthaber.com/ }\end{array}$ & $\begin{array}{c}\text { https://www. } \\
\text { facebook. } \\
\text { com/trthaber }\end{array}$ & $\begin{array}{c}\text { https:// } \\
\text { twitter.com/ } \\
\text { trthaber }\end{array}$ & $\begin{array}{c}\text { https:// } \\
\text { www.you- } \\
\text { tube.com/ } \\
\text { trthaber }\end{array}$ & $\begin{array}{c}\text { https://www. } \\
\text { instagram. } \\
\text { com/trtha- } \\
\text { ber/ }\end{array}$ \\
\hline
\end{tabular}




\begin{tabular}{|c|c|c|c|c|c|}
\hline TRT Spor & $\begin{array}{l}\text { https://www. } \\
\text { trtspor.com.tr/ }\end{array}$ & $\begin{array}{l}\text { https://www. } \\
\text { facebook. } \\
\text { com/TRTSpor }\end{array}$ & $\begin{array}{c}\text { https:// } \\
\text { twitter.com/ } \\
\text { trtspor }\end{array}$ & $\begin{array}{l}\text { https:// } \\
\text { www.you- } \\
\text { tube.com/ } \\
\text { trtspor }\end{array}$ & $\begin{array}{l}\text { https://www. } \\
\text { instagram. } \\
\text { com/trtspor/ }\end{array}$ \\
\hline TRT Avaz & $\begin{array}{l}\text { https://www. } \\
\text { trtavaz.com.tr/ }\end{array}$ & $\begin{array}{c}\text { https://www. } \\
\text { facebook. } \\
\text { com/trtavaz }\end{array}$ & $\begin{array}{c}\text { https:// } \\
\text { twitter.com/ } \\
\text { trtavaz }\end{array}$ & $\begin{array}{l}\text { https:// } \\
\text { www.you- } \\
\text { tube.com/ } \\
\text { trtavaz }\end{array}$ & $\begin{array}{l}\text { https://www. } \\
\text { instagram. } \\
\text { com/trtavaz/ }\end{array}$ \\
\hline $\begin{array}{l}\text { TRT Belge- } \\
\text { sel }\end{array}$ & $\begin{array}{c}\text { https://www. } \\
\text { trtbelgesel. } \\
\text { com.tr/ }\end{array}$ & $\begin{array}{l}\text { https://www. } \\
\text { facebook. } \\
\text { com/trtbel- } \\
\text { gesel/ }\end{array}$ & $\begin{array}{c}\text { https:// } \\
\text { twitter.com/ } \\
\text { trtbelgesel }\end{array}$ & $\begin{array}{c}\text { https:// } \\
\text { www.youtu- } \\
\text { be.com/c/ } \\
\text { trtbelgesel }\end{array}$ & $\begin{array}{c}\text { https://www. } \\
\text { instagram. } \\
\text { com/trtbel- } \\
\text { gesel/ }\end{array}$ \\
\hline TRT Müzik & $\begin{array}{l}\text { https://www. } \\
\text { trtmuzik.net. } \\
\text { tr/ }\end{array}$ & $\begin{array}{l}\text { https://www. } \\
\text { facebook. } \\
\text { com/TRT- } \\
\text { Muzik }\end{array}$ & $\begin{array}{c}\text { https:// } \\
\text { twitter.com/ } \\
\text { TRTMuzik }\end{array}$ & $\begin{array}{l}\text { https:// } \\
\text { www.you- } \\
\text { tube.com/ } \\
\text { TRTMuzik }\end{array}$ & $\begin{array}{c}\text { https://www. } \\
\text { instagram. } \\
\text { com/TRTMu- } \\
\text { zik/ }\end{array}$ \\
\hline TRT Arabi & $\begin{array}{l}\text { https://www. } \\
\text { trtarabi.com/ }\end{array}$ & $\begin{array}{c}\text { https://www. } \\
\text { facebook. } \\
\text { com/TRTA- } \\
\text { rabi/ }\end{array}$ & $\begin{array}{c}\text { https:// } \\
\text { twitter.com/ } \\
\text { trtarabi }\end{array}$ & $\begin{array}{l}\text { https:// } \\
\text { www.you- } \\
\text { tube.com/ } \\
\text { trtalarabiya }\end{array}$ & $\begin{array}{c}\text { https://www. } \\
\text { instagram. } \\
\text { com/trta- } \\
\text { rabi/ }\end{array}$ \\
\hline TRT Türk & $\begin{array}{l}\text { https://www. } \\
\text { trtturk.com.tr/ }\end{array}$ & $\begin{array}{l}\text { https://www. } \\
\text { facebook. } \\
\text { com/trtturk/ }\end{array}$ & $\begin{array}{c}\text { https:// } \\
\text { twitter.com/ } \\
\text { trtturk }\end{array}$ & $\begin{array}{l}\text { https:// } \\
\text { www.you- } \\
\text { tube.com/ } \\
\text { trtturktv }\end{array}$ & $\begin{array}{l}\text { https://www. } \\
\text { instagram. } \\
\text { com/trtturk/ }\end{array}$ \\
\hline TRT Kurdî & $\begin{array}{l}\text { https://trtkur- } \\
\text { di.com.tr/ }\end{array}$ & $\begin{array}{l}\text { https://www. } \\
\text { facebook. } \\
\text { com/TRTKur- } \\
\text { diTV }\end{array}$ & $\begin{array}{c}\text { https:// } \\
\text { twitter.com/ } \\
\text { TRTKurdiTV }\end{array}$ & $\begin{array}{c}\text { https:// } \\
\text { www.you- } \\
\text { tube.com/ } \\
\text { user/trt- } \\
\text { ses6/fea }\end{array}$ & $\begin{array}{c}\text { https://www. } \\
\text { instagram. } \\
\text { com/trtkur- } \\
\text { ditv/ }\end{array}$ \\
\hline TRT Çocuk & $\begin{array}{l}\text { https://www. } \\
\text { trtcocuk.net. } \\
\text { tr/ }\end{array}$ & $\begin{array}{l}\text { https://www. } \\
\text { facebook. } \\
\text { com/trtcocuk }\end{array}$ & $\begin{array}{c}\text { https:// } \\
\text { twitter.com/ } \\
\text { trtcocuk }\end{array}$ & $\begin{array}{l}\text { https:// } \\
\text { www.you- } \\
\text { tube.com/ } \\
\text { trtcocuk }\end{array}$ & $\begin{array}{c}\text { https://www. } \\
\text { instagram. } \\
\text { com/trtco- } \\
\text { cuk/ }\end{array}$ \\
\hline
\end{tabular}

\section{TRT'nin Sosyal Medya Evreni}

\subsection{TRT Televizyon Kanallarının Sosyal Medya İçerikleri ve Takipçileri}

2021 yılı itibariyle dünyada en çok kullanılan sosyal medya hesapları arasında 2.8 milyar kullanıcıyla Facebook, 2,2 milyar kullanıcıyla YouTube, 2 milyar kullanıcıyla Whatsapp ve 1,3 milyar kullanıcıyla Instagram platformu yer almaktadır (Statistica, 2021). Bu çerçevede Whatsapp platformun kapalı bir sosyal medya platformu olması nedeniyle liste dışı bırakılırsa TRT çatısı altındaki televizyon kanallarının tamamının dünyada en çok kullanılan ilk dört sosyal medya platformunu etkin bi- 
çimde kullandığı gözlemlenmektedir. Kısaca söz etmek gerekirse Facebook 2004 yılında faaliyete geçen bir sosyal ağ, YouTube 2005 yılında kurulan bir video payIaşım platformu, Twitter 2006 yılında kurulmuş bir mikroblog ve Instagram 2010 yılında faaliyete geçen fotoğraf ve video paylaşım platformudur. Bu platformların farklı özelliklere sahip olduğunun da vurgulanması gerekir. Twitter'ın ve Instagram'ın fotoğraf ağırlıklı platformlar olmasına rağmen bu ortamlarda yaklaşık iki dakikalık videoların paylaşılması mümkündür. Diğer yandan YouTube'un video izleme ve paylaşma platformu olması nedeniyle televizyon programları kısaltılmadan geleneksel televizyon yayınındaki özgün hâlleri ile paylaşılması mümkündür.

İncelenen kanalların Twitter ve Youtube platformlarının açılış yıllarına bakıldığında TRT Türk kanalının Twitter hesabının 2009 yılında açılması dışında diğer hesapların WEB 3.0 döneminde yani 2010 ve sonrasında açıldığı belirlenmiştir. TRT 1 (2011) , TRT 2 (2017) TRT World (2015), TRT Belgesel (2011) hem Twitter hem de YouTube kanallarının aynı yıl açıldığı, TRT Haber (2010), TRT Spor (2011), TRT Müzik (2011), TRT Türk (2009), TRT Kurdî (2011) ve TRT Çocuk'un (2010) Twitter hesaplarının YouTube kanallarından önce açıldığı gözlemlenmiştir (Şekil 1).

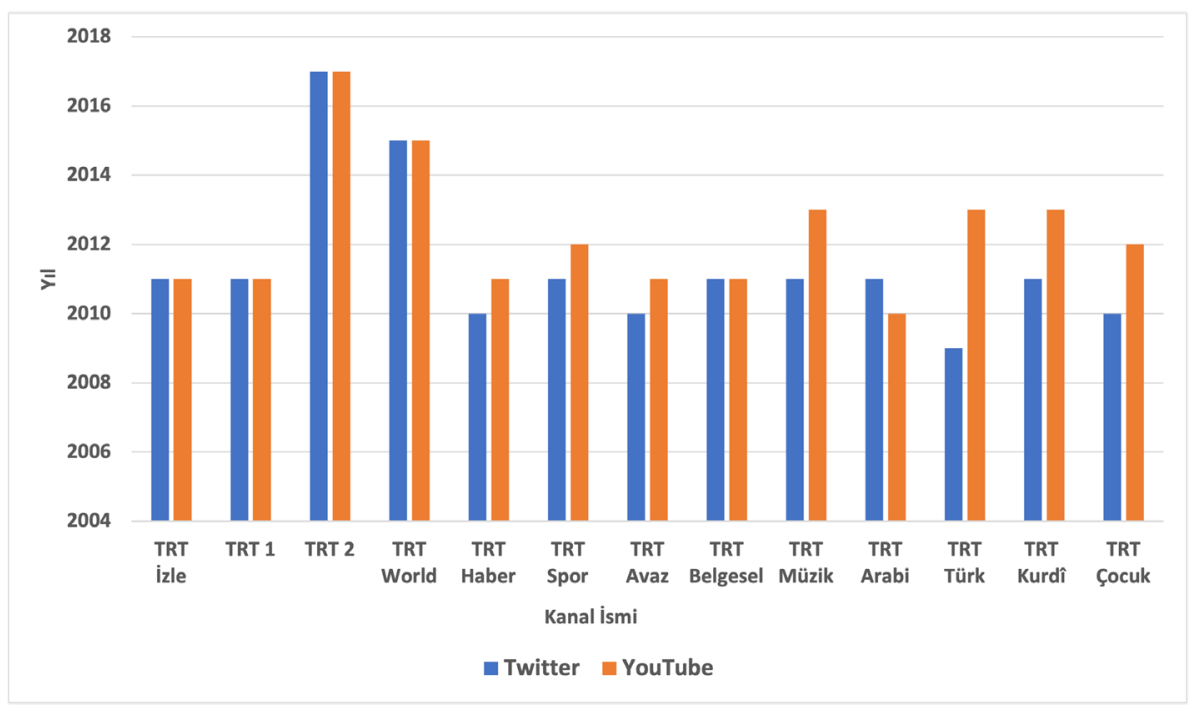

Şekil 1. Twitter ve Youtube Hesaplarının Açılış Yıllarına Göre Dağılımı

Kanalların toplam sosyal medya paylaşımlarına bakıldığında platformlar arasında dengeli bir dağılım olmadığı belirlenmiştir, buna göre toplamda en çok paylaşım yapılan platform açık ara Twitter (1.334.911 ileti) olurken bunu sırasıyla YouTube (129.086 video) ve Instagram (117.486 gönderi) platformları takip etmektedir. Hesapların ileti sayılarının dağılımı ayrıntılı olarak incelendiğinde Twitter'da 
yüz bin ve üzeri paylaşım yapan hesaplar sırasıyla TRT Spor (317.000), TRT Haber (235.000), TRT Türk (186.000), TRT World (160.500), TRT Arabi (132.800) kanallarının hesaplarıdır. Instagram platformunda ise TRT Haber (23.598), TRT 1 (15.996), TRT Arabi (14.597), TRT Spor (14.045) kanalının on bin ve üzerinde paylaşım yaptığı belirlenmiştir. Yukarıda belirtildiği üzere Twitter'a ve Instagram'a kıyasla Youtube'un bir video izleme platformu olması nedeniyle doğrudan televizyon programlarının bu platform üzerinden izlenmesi mümkündür. YouTube kanalı içerisindeki dağılıma bakıldığında on bin video ve üzerinde video barındıran YouTube kanalları sırasıyla TRT World (42.614), TRT Haber (18.237), TRT Avaz (16.744), TRT Arabi (11.907) kanallarıdır (Şekil 2).

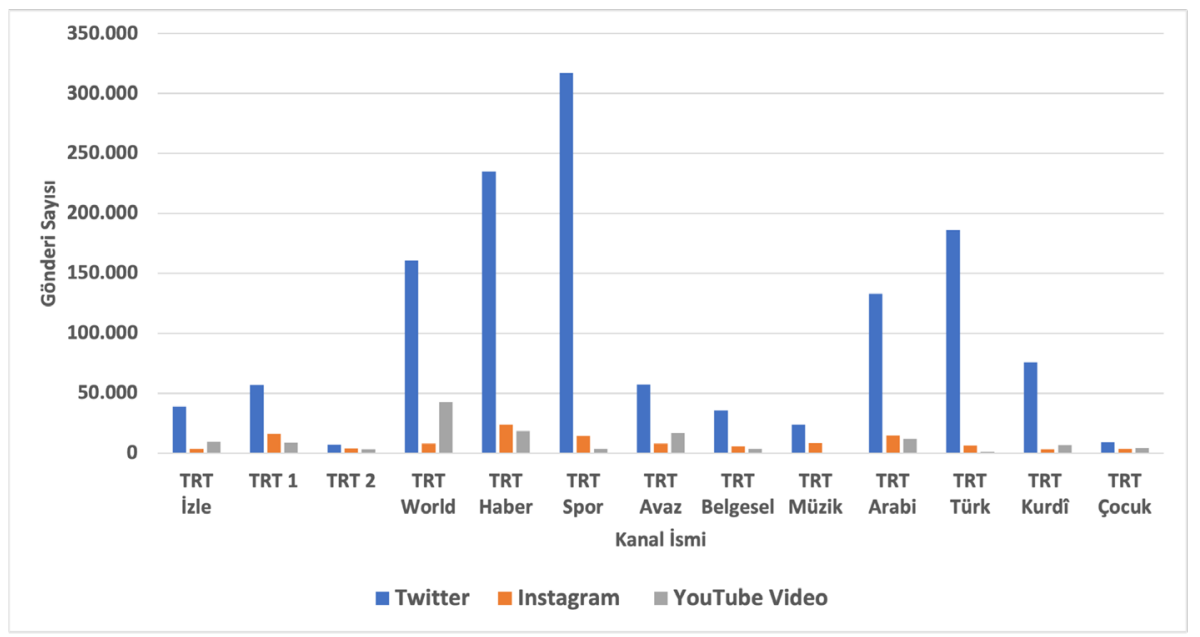

Şekil 2. Sosyal Medya Gönderi Sayıları

Ancak video izlenme sayılarına bakıldığında kanallar arası önemli farklılıkların oluştuğu gözlemlenmektedir. Buna göre TRT Çocuk kanalının diğer YouTube kanallarına göre 4.381.169.129 izleme ile öncü konumdadır. Bu kanalın ardından TRT İzle neredeyse yarısı kadar bir izleme sayısıyla 2.736.987.743 kez izlenirken, bu kanalı 2.317.337.541 izleme ile TRT 1 takip etmektedir. Diğer kanallar ise beşyüz milyon izlemenin altında kalmıştır; TRT World (457.148.510), TRT Arabi (392.928.268), TRT Haber (323.209.703), TRT Avaz (287.340.859), TRT Belgesel (183.265.461),TRT Kurdî (77.138.898), TRT Spor (71.568.215), TRT 2 (47.665.890), TRT Türk (8.110.148), TRT Müzik (1.252.697) (Şekil 3). 


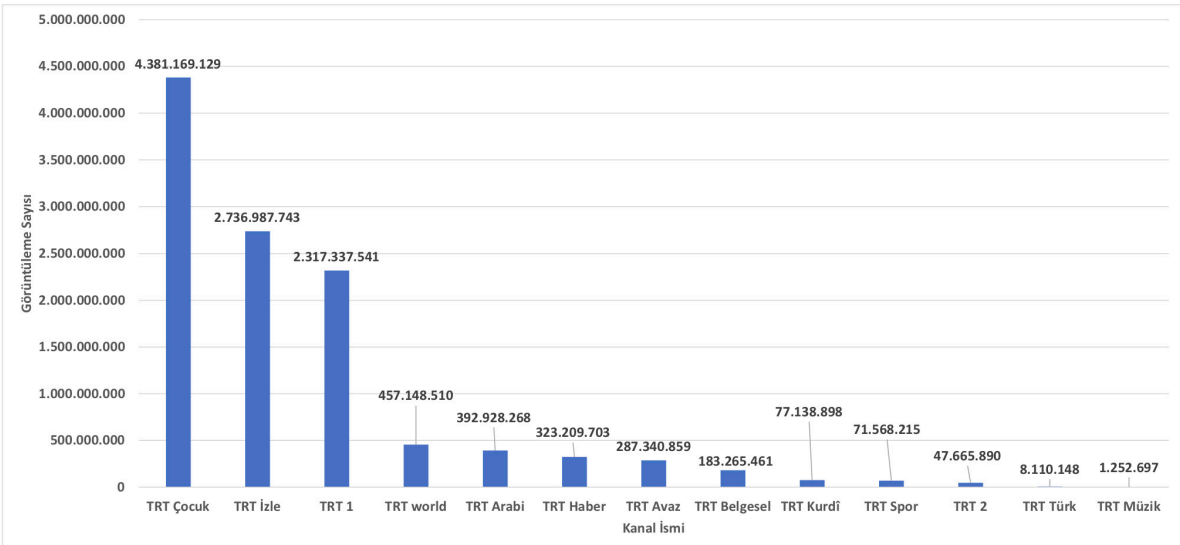

Şekil 3. YouTube Kanallarının Görüntülenme Sayıları

Diğer taraftan kanalların takipçi sayıları ve paylaşılan içerik sayıları arasında da dengeli bir dağılım olmadığı belirlenmiştir. Bir milyonun üzerinde takipçiye sahip sadece üç hesap bulunmaktadır TRT Haber (3.832.476), TRT Spor (1.783.925), TRT Arabi (1.300.000). YouTube abone sayılarına bakıldığında ise bir milyonun üzerinde aboneye sadece TRT Çocuk (5.100.000), TRT 1 (3.640.000), TRT İzle (3.600.000), TRT World (1.430.000) kanallarının sahip olduğu görülmektedir. Instagram platformunda ise TRT Haber (1.900.000), TRT Belgesel (1.600.000), TRT Arabi (1.200.000) ve TRT 1 (1.000.000) hesaplarının bir milyonun üzerinde takipçisi bulunmaktadır (Şekil 4).

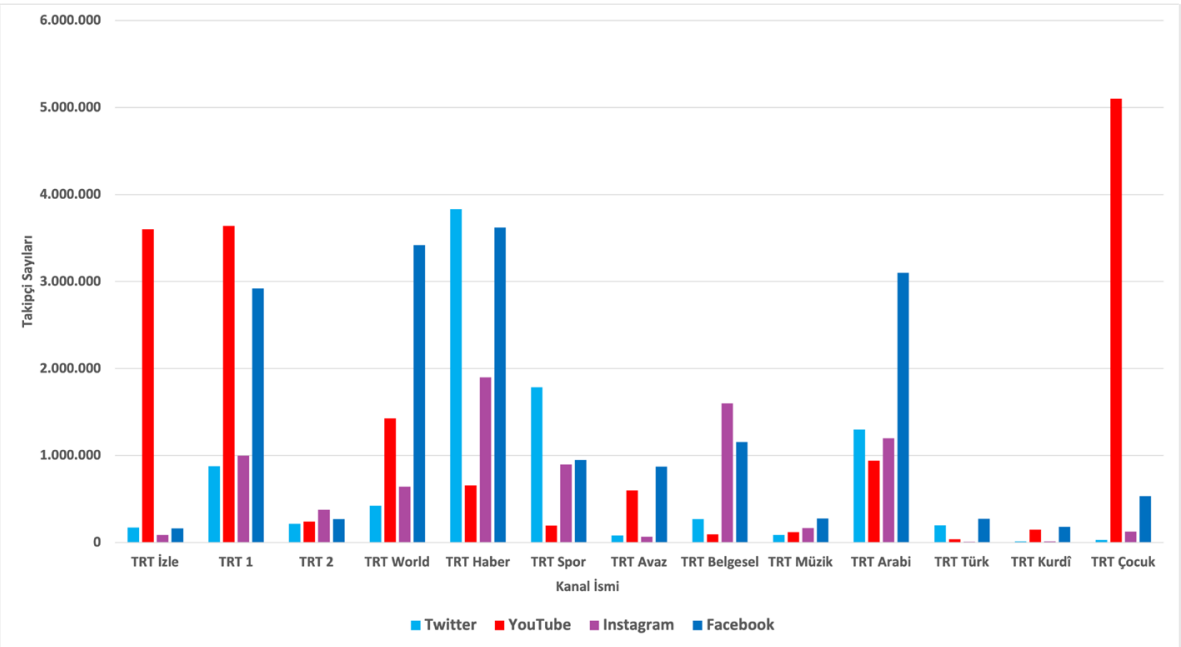

Şekil 4. Sosyal Medya Platformlarının Sosyal Medya Takipçi Sayıları 
Televizyon kanallarının sosyal medya hesapları arasında gerek paylaşılan içerik sayısında gerekse takipçi sayılarında büyük farklılıklar bulunmaktadır. Söz konusu bu platformlar arasındaki farklılıklar sosyal medya içerik yöneticilerinin uyguladıkları içerik yönetim pratiklerinin başarılı ya da başarız olmasının ötesinde bir durum yaşanmaktadır. Burada televizyon kanalının hedef kitlesinin sosyal medya alışkanlıkları ve bu platformları kullanım biçimleri; izlenme ve takipçi sayılarındaki farklılıkların temelini oluşturmaktadır. Örneğin TRT Çocuk YouTube kanalının bu denli yüksek abone ve izlenme sayılarına ulaşması, çocukların aynı içeriği farklı zamanlarda tekrar tekrar izlemeyi istemesinden kaynaklanıyor olabilir. Bunun dışında yine çocukların daha ileri yaştaki izleyicilere göre sosyal medya platformlarını daha aktif kullanması ve yeni içeriklerinden haberdar olma istekleri TRT Çocuk'un yüksek bir abone sayısına ulaşmasına neden olmuş olabilir. Sosyal medya platformlarının yapısal özellikleri nedeniyle bazı izleyici kitlelerinin belirli sosyal medya platformlarını tercih ettiğini de söylemek mümkündür. Örneğin TRT Çocuk'un Twitter takipçisi diğer Twitter hesaplarına göre oldukça düşüktür. Buna karşın Twiter haber kaynağı olarak oldukça yaygın kullanılmasından dolayı TRT Haber ve TRT Spor'un Twitter hesaplarının takipçi sayısı diğer Twitter hesaplarına kıyasla oldukça yüksektir.

\subsection{TRT Televizyon Kanallarının WEB Ortamındaki Ağ Yapılanması ve Sosyal Medya Pratikleri}

Dijital platformların ve bağlant verdikleri sosyal medya platformlarının ağ yapılanmasına bakıldığında her televizyon kanalının kendi web sayfasının bulunduğu, bu WEB sayfalarının da yine kanalın kurumsal sosyal medya hesaplarına bağlant verdiği görülmektedir. Bu çerçevede trt.net.tr'nin Türkiye Radyo Televizyon Kurumunun (TRT) ana web sayfasını oluşturduğu, bu sayfanın kurum bünyesindeki tüm radyo, televizyon, haber ve spor sayfalarına bağlant verdiği görülmektedir. Televizyon yayıncılığı için ayrı olarak tasarlanmış TRT İzle (https://www.trtizle. com) sayfasının ise TRT televizyon kanallarının ve bağlantılı sosyal medya hesaplarının çatı platformu olduğu belirlenmiştir. TRT İzle'nin Twitter hesabı, TRT televizyon kanalarının sosyal medya paylaşımlarının birçoğunu retweet ederek içerikleri yeniden dolaşıma soktuğu görülmektedir. Bir başka deyişle TRT İzle'nin hem WEB sayfası hem de Twitter ve Instagram hesabı TRT kanalarında yayınlanan program ve dizileri gösteren ana yapıdır. Yine aynı kapsamda TRT İzle YouTube kanalı TRT 1 başta olmak üzere TRT Çocuk ve TRT Belgesel gibi pek çok kanalın tam içeriklerine ve fragmanlarına erişim sağlamaktadır.

Doğrudan TRT kanallarının sosyal medya hesaplarına bakıldığında özellikle Twit- 
ter hesapları arasında farklılıklar gözlemlenmektedir. Bu farklılıklar çoğunlukla kanaların yapısal özellikleri ve hedef kitlesiyle ilişkilidir. Örneğin TRT Haber (https:// www.trthaber.com) doğrudan bir haber sitesidir. Dolayısıyla bu ortamda yayınlanan haberlerin pek çoğu ile ilgili twit de atılmakta ve okuyucular Twitter üzerinden WEB sitesine yönlendirilmektedir. Diğer yandan TRT 1 (@trt1) ve TRT 2'nin (@trt2tv) Twitter hesapları okuyucuyu/izleyiciyi geleneksel yayındaki televizyon programlarına yönlendirilmeyi amaçlamaktadır. Buna karşın TRT Çocuk (@trtcocuk) hesabı; TRT Çocuk'un dergi ve kitaplarına, WEB sitesine, çevrim içi oyunlara ya da TRT Çocuk YouTube kanalından oluşan daha geniş bir platformlar bütününe yönlendirmektedir.

Diğer yandan Twitter hesaplarında kullanılan görsel, işitsel içeriklere bakıldığında; atılan bütün twitlerde yazıyla birlikte mutlaka bir görsel ya da video bulunduğu, TRT 1'in Twitter gönderilerinin tamamının videolu paylaşımlar olduğu, TRT 2 paylaşımlarında fotoğraf ya da video kullanıldığı, TRT Çocuk hesabında ise ağırlıklı olarak video ve çizimlere yer verildiği ancak fotoğraf içeren paylaşımların oldukça az olduğu gözlemlenmiştir. Tüm bunlara ek olarak TRT'nin WEB ortamındaki televizyon yayıncılığının önemli bileşenin de TRT Arşiv olduğunu söylemek mümkündür. TRT Arşiv doğrudan bir televizyon kanalı ile ilişkili değildir. Güncel televizyon programları ve yayınları barındıran diğer sayfaların aksine, bu WEB sayfası 2000'li yılara kadar TRT televizyonlarında yayınlanmış içerikleri barındıran bir dijital video arşividir. TRT bu çevrim içi arşiv platformu, tarihsel öneme sahip pek çok içeriğe WEB sayfası ve YouTube kanalı (https://www.youtube.com/trtarsiv) üzerinden erişilmesini mümkün kılmıştır. Bu platformlardaki içerikler tematik olarak ayrılmıştir ancak gerek TRT Arşiv WEB sayfası (https://www.trtarsiv.com) gerekse TRT Arşiv YouTube kanalındaki içeriklerin hiçbirinde yapım yılının belirtilmemesi bu platformun en büyük eksikliğini oluşturmaktadır.

Araştırma kapsamında incelenen sosyal medya ve WEB sayfalarına yönelik genel bir değerlendirme yapıldığında, TRT'nin güçlü bir sosyal TV stratejisi geliştirdiği, televizyon yayıncılığı ve sosyal medya platformları arasında çok yönlü bir çapraz medya içerik döngüsü oluşturulduğunu söylemek mümkündür. Geleneksel medyada yayımlanan içeriklerden türetilen mikro içerikler Twitter, Instragram ve Facebook gibi sosyal medya platformları ve YouTube video paylaşım platformu üzerinden paylaşıldığı görülmüştür. Buna karşın oluşturulan sosyal TV ekosistemi içerisinde birbirini bütünleyen, genel öyküye farklı ölçülerde katkı sağlayan transmedya tabanlı dijital anlatımların ve etkileşimli TV programlarının bulunmadığı belirlenmiştir. Bu anlamda sosyal TV içeriklerinin yayımlanan mecralara özgü olarak geleneksel medya içeriklerinden uyarlandığı ancak doğrudan sosyal medya ve 
WEB sayfaları için özel içeriklerin oluşturulmadığı görülmüştür. Benzer sonuçlara Kanal D ve Star TV kanallarının yeni medya stratejilerine odaklanan çalışmalarda da rastlanmıştır (Dikmen, 2016; 2017). Diğer yandan televizyon yayıncılığındaki genel eğilime bakıldığında, etkileşimli içeriklerin geleneksel televizyon yayıncılığının sosyal medya platformlarında kullanılmazken daha çok Netflix gibi seç-izle platformlarında kullanıldığı göz ardı edilmemelidir.

\section{Sonuç}

Televizyon yayıncılığının bugün geldiği noktada, sosyal medya platformları ile bütünleşik bir yayıncılık modeli oluşturduğunu söylemek mümkündür. İzleyicilerin sadece birbirleriyle iletişim kurmasını hedefleyen donanım tabanlı sosyal TV 1.0 dönemi kısa sürede geride bırakılmıştır. Bunun yerine izleyicilerin gündelik yaşamında kullandığı sosyal medya platformlarına dâhil olan sosyal TV 2.0 dönemine adım atımıştır. Bu geçiş, aynı zamanda geleneksel televizyon yayıncılığı için de önemli bir kırılma oluşturmaktadır. Televizyon yayıncılığı, geleneksel ortamda yayınladığı içerikleri dönüştürerek her bir sosyal medya platformunun kendine özgü biçimleriyle sınırlandırılmış bir ortamda içerikler paylaşmaktadır. Sosyal medya platformlarının bu kalıplaşmış yapıları içerisinde, televizyon kanalları fotoğraf, kısa video ve yazılı iletileri birlikte kullanarak içerikleri paylaşmaktadır. Her iletide kullanılacak karakter ve fotoğraf sayısının sınırlı olduğu ve ancak kısa süreli videoların paylaşılabildiği bir ortamda, televizyon kuruluşları, izleyicinin ilgisini belirli programlara ya da içeriklere yönlendirmeye çalışmaktadır.

Bu çerçevede araştırma kapsamında incelenen sosyal medya hesaplarının her birinde farklı sayısal pratikler yürütüldüğü ortaya çıkmıştır. TRT Arşiv sitesi üzerinden, TRT'de yayımlanmış tarihi değere sahip içeriklerin internet üzerinden açık erişime açılması, televizyon yayıncılığı için önemli bir adım oluşturmuştur. Her kanalın geleneksel televizyon yayınındaki hedef kitlesine göre uyarlanmış bir çapraz medya içerik üretimi ve yönetimi geliştirdiği belirlenmiştir. Bu kapsamda TRT çatısı altında yayın yapan bütün televizyon kanallarının ayrı sosyal medya hesaplarına sahip olduğu, bu hesapların birbiriyle oldukça girift bir yapı içerisinde olduğu, hesaplar arasında içeriklerin yeniden dolayımlandığı belirlenmiştir. Oluşan bu sosyal TV yapılanmasına bakıldığında televizyon yayıncılığı ve sosyal medya platformları arasında çok yönlü bir çapraz medya içerik dolaşımının oluşturulmasına rağmen bu ekosistem içerisinde transmedya tabanlı dijital anlatımların ve etkileşimli TV programlarının bulunmadığı belirlenmiştir. Diğer yandan etkileşimli içeriklerin geleneksel televizyon kanallarının sosyal medya platformlarında kullanılmazken daha çok Netflix gibi seç-izle platformlarında kullanıldığı da dikkat 
çekmektedir. Bu çerçevede Netflix'e rakip olacağı düşünülen (T24, 2021) TRT'nin henüz yayına başlamamış tasarım aşamasındaki yeni dijital platformu TRT 0'da etkileşimli ve/veya transmedya içeriklerin yayımlanması muhtemeldir. Bu nedenle Türkiye'deki yayıncılık ekosisteminde bulunan seç-izle platformlarına yönelik araştırmaların artması büyük önem taşımaktadır.

\section{Çıkar Çatışması Beyanı}

Makale yazarları herhangi bir çıkar çatışması olmadığını beyan etmiştir.

\section{Kaynakça}

BBC. (2004, Haziran 29). Building public value - Renewing the BBC for a digital world. BBC. Erişim adresi: https://www.bbc.co.uk/pressoffice/pressreleases/ stories/2004/06_june/29/bpv.shtml (Erişim Tarihi: 1 Ekim 2021).

Bolat, N. (2019). Geleneksel mecralarda çapraz medya ve transmedya anlatıları üzerine bir inceleme: Ağır Roman örneği. Selçuk Illetişim, 12(2), 503-531.

Chorianopoulos, K., ve Lekakos, G. (2008). Introduction to Social TV: Enhancing the Shared Experience with Interactive TV. International Journal of Human-Computer Interaction, 24(2), 113-120.

Dikmen, E. Ş. (2016). Türkiye'de televizyon yayıncılığının yeni medya yapılanması: Televizyon ve teknoloji ekseninde eleştirel bir değerlendirme. Ankara Üniversitesi, Radyo, televizyon ve Sinema. Ankara: Yükseköğretim Kurulu Başkanlığı Tez Merkezi.

Dikmen, E. Ş. (2017). Türkiye'de Televizyon Yayıncılığının Dönüşümü: Sosyal TV Yayıncılığı. Gümüşhane Üniversitesi İletişim Fakültesi Elektronik Dergisi, 5(1), 425-448.

Garipoğlu, T. (1993). Hugo. Kanal 6 Televizyon Kanalı.

Gezgin, S. (2018). Televizyon 4.0. TRT Akademi, 3(6), 580-589.

Harrington, S., Highfield, T., ve Bruns, A. (2013). More than a backchannel: Twitter and television. Participations, 10(1), 405-409.

Holat, O. (2021). Dijital platform Netflix'in la casa de papel dizisinde çapraz medya stratejisinin inşası. İletişim Çalışmaları Dergisi, 7(3), 503-521.

Jenkins, H. (2006). Convergence Culture. New York University Press.

O'Sullivan, D. (1995). The Prisoner Chat. Erişim adresi: https://itp.nyu.edu/ dbo3/proj/ prisoner.htm (Erişim Tarihi: 1 Ekim 2021).

Regan, T., ve Todd, L. (2004). Media center buddies: instant messaging around a media center. Proceedings of the third Nordic conference on Human-computer interaction, 141-144. 
Schatz, R., Baillie, L., Fröhlich, P., ve Egger, S. (2008). Getting the Couch Potato to Engage in Conversation: Social TV in a Converging Media Environment. Proceedings, Workshop at EurolTV 2008, . Salzburg.

Statistica. (2021). Most popular social networks worldwide as of July 2021, ranked by number of active users. Erişim adresi: https://www.statista.com/statistics /272014/global-social-networks-ranked-by-number-of-users/ (Erişim Tarihi: 1 Ekim 2021).

Stollfuß, S. (2018). Between television, web and social media: On social TV, About:Kate and participatory production in German Public Television. Participations Journal of Audience \& Reception Studies, 15(1), 36-59.

T24 (2021). TRT'den 2 yeni dijital platform. Erişim adresi: T24.com: https://t24.com.tr/ foto-haber/trt-den-2-yeni-dijital-platform,11519 (Erişim Tarihi: 1 Ekim 2021).

TRT Arabi (2021). TRT Arabi. (Türkiye Radyo Televizyon Kurumu) Erişim adresi: https:// www.trtarabi.com/ (Erişim Tarihi: 1 Eylül 2021).

TRT Arabi @trtarabi. (2021). Twitter@trtarabi. (Twitter Inc Twtr) Erişim adresi: https:// twitter.com/trtarabi (Erişim Tarihi: 1 Eylül 2021).

TRT Arabi Facebook. (2021). TRT Arabi Facebook. (Meta Platforms, Inc.) Erişim adresi: https://www.facebook.com/TRTArabi// (Erişim Tarihi: 1 Eylül 2021).

TRT Arabi Instagram. (2021). TRT Arabi Instagram. (Meta Platforms, Inc.) Erişim adresi: https://www.instagram.com/trtarabi (Erişim Tarihi: 1 Eylül 2021).

TRT Arabi YouTube. (2021). TRT Arabi YouTube. (Google LLC) Erişim adresi: https://www. youtube.com/trtalarabiya (Erişim Tarihi: 1 Eylül 2021).

TRT Arşiv (2021). TRT Arşiv (Türkiye Radyo Televizyon Kurumu) Erişim Adresi: https:// www.trtarsiv.com/ (Erişim Tarihi: 1 Eylül 2021).

TRT Arşiv YouTube. (2021). TRT Arşiv YouTube. (Google LLC) Erişim adresi: https://www. youtube.com/trtarsiv (Erişim Tarihi: 1 Eylül 2021).

TRT Avaz @trtavaz. (2021). Twitter@trtavaz. (Twitter Inc Twtr) Erişim adresi: https:// twitter.com/trtavaz (Erişim Tarihi: 1 Eylül 2021).

TRT Avaz Facebook. (2021). TRT Avaz Facebook. (Meta Platforms, Inc.) Erişim adresi: https://www.facebook.com/trtavaz (Erişim Tarihi: 1 Eylül 2021).

TRT Avaz Instagram. (2021). TRT Avaz Instagram. (Meta Platforms, Inc.) Erişim adresi: https://www.instagram.com/trtavaz/ (Erişim Tarihi: 1 Eylül 2021).

TRT Avaz OK. (2021) TRT Avaz OK. (VKontakte) Erişim adresi: https://ok.ru/group /54387896484012 (Erişim Tarihi: 1 Eylül 2021).

TRT Avaz VK. (2021) TRT Avaz VK. (VKontakte) Erişim adresi: https://vk.com/trtavaz (Erişim Tarihi: 1 Eylül 2021).

TRT Avaz YouTube. (2021). TRT Avaz YouTube. (Google LLC) Erişim adresi: https://www. youtube.com/trtavaz (Erişim Tarihi: 1 Eylül 2021). 
TRT Avaz. (2021). TRT Avaz. (Türkiye Radyo Televizyon Kurumu) Erişim adresi: https:// www.trtavaz.com.tr/ (Erişim Tarihi: 1 Eylül 2021).

TRT Belgesel (2021). TRT Belgesel. (Türkiye Radyo Televizyon Kurumu) Erişim adresi: https://www.trtbelgesel.com.tr/ (Erişim Tarihi: 1 Eylül 2021).

TRT Belgesel @belgesel. (2021). Twitter@trtbelgesel. (Twitter Inc Twtr) Erişim adresi: https://twitter.com/trtbelgesel (Erişim Tarihi: 1 Eylül 2021).

TRT Belgesel Facebook. (2021). TRT Belgesel Facebook. (Meta Platforms, Inc.) Erişim adresi: https://www.facebook.com/trtbelgesel/ (Erişim Tarihi: 1 Eylül 2021).

TRT Belgesel Instagram. (2021). TRT Belgesel Instagram. (Meta Platforms, Inc.) Erişim adresi: https://www.instagram.com/trtbelgesel/ (Erişim Tarihi: 1 Eylül 2021).

TRT Belgesel YouTube. (2021). TRT Belgesel YouTube. (Google LLC) Erişim adresi: https:// www.youtube.com/c/trtbelgesel (Erişim Tarihi: 1 Eylül 2021).

TRT Çocuk (2021). TRT Çocuk (Türkiye Radyo Televizyon Kurumu) Erişim adresi: https:// www.trtcocuk.net.tr/ (Erişim Tarihi: 1 Eylül 2021).

TRT Çocuk @trtcocuk. (2021). Twitter@trtturk. (Twitter Inc Twtr) Erişim adresi: https:// www.youtube.com/trtcocuk (Erişim Tarihi: 1 Eylül 2021).

TRT Çocuk Facebook. (2021). TRT Çocuk Facebook. (Meta Platforms, Inc.) Erişim adresi: https://twitter.com/trtcocuk (Erişim Tarihi: 1 Eylül 2021).

TRT Çocuk Instagram. (2021). TRT Çocuk Instagram. (Meta Platforms, Inc.) Erişim adresi: https://www.instagram.com/trtcocuk/ (Erişim Tarihi: 1 Eylül 2021).

TRT Çocuk YouTube. (2021). TRT Çocuk YouTube. (Google LLC) Erişim adresi: https://www. youtube.com/trtcocuk (Erişim Tarihi: 1 Eylül 2021).

TRT Haber @trthaber. (2021). Twitter@trthaber. (Twitter Inc Twtr) Erişim adresi: https:// twitter.com/trthaber (Erişim Tarihi: 1 Eylül 2021).

TRT Haber Facebook. (2021). TRT Haber Facebook. (Meta Platforms, Inc.) Erişim adresi: https://www.facebook.com/trthaber (Erişim Tarihi: 1 Eylül 2021).

TRT Haber Instagram. (2021). TRT Haber Instagram. (Meta Platforms, Inc.) Erişim adresi: https://www.instagram.com/trthaber (Erişim Tarihi: 1 Eylül 2021).

TRT Haber YouTube. (2021). TRT Haber YouTube. (Google LLC) Erişim adresi: https://www. youtube.com/trthaber (Erişim Tarihi: 1 Eylül 2021).

TRT Haber. (2021). TRT Haber. (Türkiye Radyo Televizyon Kurumu) Erişim adresi: https:// www.trthaber.com/ (Erişim Tarihi: 1 Eylül 2021).

TRT Kurdi (2021). TRT Kurdi. (Türkiye Radyo Televizyon Kurumu) Erişim adresi: https:// trtkurdi.com.tr/ (Erişim Tarihi: 1 Eylül 2021).

TRT Kurdi @trtavaz. (2021). Twitter@trtturk. (Twitter Inc Twtr) Erişim adresi: https://twitter.com/TRTKurdiTV (Erişim Tarihi: 1 Eylül 2021). 
TRT Kurdi Facebook. (2021). TRT Türk Facebook. (Meta Platforms, Inc.) Erişim adresi: https://www.facebook.com/TRTKurdiTV (Erişim Tarihi: 1 Eylül 2021).

TRT Kurdi Instagram. (2021). TRT Kurdi Instagram. (Meta Platforms, Inc.) Erişim adresi: https://www.instagram.com/trtkurditv/ (Erişim Tarihi: 1 Eylül 2021).

TRT Kurdi YouTube. (2021). TRT Kurdi YouTube. (Google LLC) Erişim adresi: https://www. youtube.com/user/trtses6/fea (Erişim Tarihi: 1 Eylül 2021).

TRT Müzik (2021). TRT Müzik. (Türkiye Radyo Televizyon Kurumu) Erişim adresi: https:// www.trtmuzik.net.tr/ (Erişim Tarihi: 1 Eylül 2021).

TRT Müzik@muzik. (2021). Twitter@trtmuzik. (Twitter Inc Twtr) Erişim adresi: https:// twitter.com/TRTMuzik (Erişim Tarihi: 1 Eylül 2021).

TRT Müzik Facebook. (2021). TRT Müzik Facebook. (Meta Platforms, Inc.) Erişim adresi: https://www.facebook.com/TRTMuzik / (Erişim Tarihi: 1 Eylül 2021).

TRT Müzik Instagram. (2021). TRT Müzik Instagram. (Meta Platforms, Inc.) Erişim adresi: https://www.instagram.com/TRTMuzik/ (Erişim Tarihi: 1 Eylül 2021).

TRT Müzik YouTube. (2021). TRT Müzik YouTube. (Google LLC) Erişim adresi: https://www. youtube.com/TRTMuzik (Erişim Tarihi: 1 Eylül 2021).

TRT Spor @trtspor. (2021). Twitter@trthaber. (Twitter Inc Twtr) Erişim adresi: https:// twitter.com/trtspor (Erişim Tarihi: 1 Eylül 2021).

TRT Spor Facebook. (2021). TRT Spor Facebook. (Meta Platforms, Inc.) Erişim adresi: https://www.facebook.com/TRTSpor (Erişim Tarihi: 1 Eylül 2021).

TRT Spor Instagram. (2021). TRT Spor Instagram. (Meta Platforms, Inc.) Erişim adresi: https://www.instagram.com/trtspor/ (Erişim Tarihi: 1 Eylül 2021).

TRT Spor YouTube. (2021). TRT Spor YouTube. (Google LLC) Erişim adresi: https://www. youtube.com/trtspor (Erişim Tarihi: 1 Eylül 2021).

TRT Spor. (2021). TRT Spor. (Türkiye Radyo Televizyon Kurumu) Erişim adresi: https:// www.trtspor.com.tr/ (Erişim Tarihi: 1 Eylül 2021).

TRT Türk (2021). TRT Türk. (Türkiye Radyo Televizyon Kurumu) Erişim adresi: https://www. trtturk.com.tr/ (Erişim Tarihi: 1 Eylül 2021).

TRT Türk @trtturk. (2021). Twitter@trtturk. (Twitter Inc Twtr) Erişim adresi: https:// twitter.com/trtturk (Erişim Tarihi: 1 Eylül 2021).

TRT Türk Facebook. (2021). TRT Türk Facebook. (Meta Platforms, Inc.) Erişim adresi: https://www.facebook.com/trtturk/ (Erişim Tarihi: 1 Eylül 2021).

TRT Türk Instagram. (2021). TRT Türk Instagram. (Meta Platforms, Inc.) Erişim adresi: https://www.instagram.com/trtturk/ (Erişim Tarihi: 1 Eylül 2021).

TRT Türk YouTube. (2021). TRT Türk YouTube. (Google LLC) Erişim adresi: https://www. youtube.com/trtturktv (Erişim Tarihi: 1 Eylül 2021). 
TRT World @trtworld. (2021). Twitter@trtworld. (Twitter Inc Twtr) Erişim adresi: https:// twitter.com/trtworld (Erişim Tarihi: 1 Eylül 2021).

TRT World Instagram. (2021). TRT Word Instagram. (Meta Platforms, Inc.) Erişim adresi: https://www.instagram.com/trtword (Erişim Tarihi: 1 Eylül 2021).

TRT World YouTube. (2021). TRT Word YouTube. (Google LLC) Erişim adresi: https://www. youtube.com/c/trtworld (Erişim Tarihi: 1 Eylül 2021).

TRT World Facebook. (2021). TRT Word Facebook. (Meta Platforms, Inc.) Erişim adresi: https://www.facebook.com/trtworld (Erişim Tarihi: 1 Eylül 2021).

TRT World. (2021). TRT World. (Türkiye Radyo Televizyon Kurumu) Erişim adresi: https:// www.trtworld.com/ (Erişim Tarihi: 1 Eylül 2021).

TRT1 @trt1. (2021). Twitter@trt1. (Twitter Inc Twtr) Erişim adresi: https://twitter.com/ TRT1 (Erişim Tarihi: 1 Eylül 2021).

TRT1 Facebook. (2021). TRT1 Facebook. (Meta Platforms, Inc.) Erişim adresi: https:// www.facebook.com/TRT1 (Erişim Tarihi: 1 Eylül 2021).

TRT1 Instagram. (2021). TRT1 Instagram. (Meta Platforms, Inc.) Erişim adresi: https:// www.instagram.com/trt1 (Erişim Tarihi: 1 Eylül 2021).

TRT1 YouTube. (2021). TRT1 YouTube. (Google LLC) Erişim adresi: TRT1: https://www. youtube.com/user/trttv1 (Erişim Tarihi: 1 Eylül 2021).

TRT1. (2021). TRT1. (Türkiye Radyo Televizyon Kurumu) Erişim adresi: TRT1: https://www. trt1.com.tr/ (Erişim Tarihi: 1 Eylül 2021).

TRT2 Facebook. (2021). TRT2 Facebook. (Meta Platforms, Inc.) Erişim adresi: https:// www.facebook.com/trt2 (Erişim Tarihi: 1 Eylül 2021).

TRT2 Instagram. (2021). TRT2 Instagram. (Meta Platforms, Inc.) Erişim adresi: https:// www.instagram.com/trt2/ (Erişim Tarihi: 1 Eylül 2021).

TRT2 Twitter. (2021). Twitter@trt2. (Twitter Inc Twtr) Erişim adresi: https://twitter.com/ trt2tv (Erişim Tarihi: 1 Eylül 2021).

TRT2 YouTube. (2021). TRT2 YouTube. (Google LLC) Erişim adresi: https://www.youtube. com/trt2 (Erişim Tarihi: 1 Eylül 2021).

TRT2. (2021). TRT2. (Türkiye Radyo Televizyon Kurumu) Erişim adresi: https://www.trt2. com.tr/ (Erişim Tarihi: 1 Eylül 2021).

Yılmaz, A. (2020). Radyo ve Sosyal Medya Yakınsaması: TRT Radyo ve TRT FM'in Facebook ve Twitter Pratikleri. TRT Akademi, 5(9), 28-51. 